\title{
Pengetahuan dan Sikap Ahli Teknologi Laboratorium Medik terhadap Standar Operasional Prosedur Penanganan Sampel Sputum
}

\section{The Knowledge and Attitude of Medical Laboratory Technologist on The Standard Operating Procedur for The Sputum Sample Handling}

\author{
Siti Munawaroh ${ }^{1}$, Isna Lailatur Rohmah ${ }^{2}$, Muhammad Rizki Kurniawan ${ }^{3}$ \\ Fakultas Sains dan Teknologi, Universitas Binawan, Indonesia
}

\section{ARTICLE INFO}

\section{Article history}

Received date

12 Apr 2021

Revised date

17 May 2021

Accepted date

22 Aug 2021

\section{Keywords:}

Attitudes;

Cibinong;

Knowledge;

Sputum.

Kata kunci:

Sikap;

Cibinong;

Pengetahuan;

Sputum.

\author{
ABSTRACT/ ABSTRAK
}

Medical Laboratory Technologist (MLT) is the medical team that examined the laboratory, including the sputum specimen, where the sputum specimen is infected that MLT must treat with care, to avoid a work accident or nosocomial infection. The purpose of this research was to find out whether there is a correlation between knowledge and attitude of MLT towards standard operating procedure (SOP) for handling Tuberculosis (TB) sputum samples. This research was conducted through an online questionnaire with a google form, where this questionnaire is filled in at the location of each MLT who works at health centers and hospitals in the Cibinong District area. Sampling techniques in the research of using purposive sampling. The research period was from June to August 2020. This research used primary data with a cross-sectional design involving 46 MLT respondents. A method of data analysis is a quantitative analysis and measured using multiple linear regression analysis. The results showed positive influence work knowledge and attitudes towards the application of SOP for handling TB sputum samples because it has the significant value of $0,012<0,05$ and Fcount $4,90>$ Ftable 3,41 with the results of the coefficient of determination (R-square) of $0,186(18,6 \%)$, therefore, we conclude that there is a correlation between MLT knowledge and attitudes towards the SOP of the handling TB sputum samples with a percentage of $18 \%$.

\begin{abstract}
Ahli Teknologi Laboratorium Medik (ATLM) merupakan tenaga kesehatan yang melakukan pemeriksaan laboratorium, salah satunya penanganan sampel sputum, dimana spesimen sputum merupakan bahan infeksius yang harus ditangani dengan hati-hati oleh ATLM, untuk menghindari terjadinya kecelakaan kerja atau penyakit nosokomial. Tujuan dari penelitian ini untuk mengetahui ada tidaknya hubungan pengetahuan dan sikap ATLM terhadap Standar Operasional Prosedur (SOP) penanganan sampel sputum tuberkulosis (TB) paru. Penelitian ini dilakukan melalui kuesioner online dengan google form, dimana kuesioner ini di isi pada tempat masing-masing ATLM yang bekerja di Puskesmas dan Rumah Sakit daerah Kecamatan Cibinong. Waktu penelitian dari bulan Juni sampai Agustus 2020. Jenis penelitian ini menggunakan data primer dengan desain cross sectional yang melibatkan 46 responden ATLM. Metode analisis data dalam penelitian menggunakan analisis kuantitatif dan di uji dengan analisis regresi berganda. Hasil penelitian menyatakan bahwa terdapat hubungan antara pengetahuan dan sikap terhadap penerapan SOP penanganan sampel sputum TB dengan nilai signifikan 0,012<0,05 dan nilai Fhitung sebesar 4,90>Ftabel 3,41 dengan hasil uji koefisien determinasi ( $R$-square) sebesar $0,186(18,6 \%)$, maka, dapat di simpulkan bahwa terdapat hubungan antara pengetahuan dan sikap ATLM terhadap SOP penanganan sampel sputum TB dengan presentase sebesar $18 \%$.
\end{abstract}

Corresponding Author:

Siti Munawaroh

Jurusan Teknologi Laboratorium Medis, Universitas Binawan, Jakarta-Indonesia

Email: smunawaroh532@gmail.com 


\section{PENDAHULUAN}

Tuberkulosis (TB) adalah penyakit menular yang disebabkan oleh bakteri Mycobacterium tuberculosis. Bakteri penyebab penyakit TB ini menyerang paru, tetapi dapat juga mengenai organ tubuh lainnya. Pasien TB paru menularkan bakteri ke udara dalam bentuk droplet (percikan). Penyakit TB merupakan penyakit yang sangat berbahaya dan mematikan, sehingga diperlukan pengendalian agar semakin bekurang angka penularan dan kematian akibat penyakit TB (Kementerian Kesehatan RI, 2016; Ekawati, 2018).

TB sampai dengan saat ini masih menjadi salah satu masalah kesehatan masyarakat di dunia. Kasus TB di Indonesia pada tahun 2017 sejumlah 442.000 kasus. WHO (World Health Organization) menargetkan penurunan angka kematian akibat TB sebesar $40 \%$ pada tahun 2020 dan menurunkan angka kesakitan sebesar $30 \%$ pada tahun 2030 (World Health Organization, 2019). Kasus TB di Jawa Barat pada tahun 2017 sebanyak 82.063 kasus, dimana jumlah kasus tersebut meningkat dari tahun 2016 yaitu 72.558 kasus. Kasus tertinggi terdapat di tiga Kabupaten/Kota yaitu Kota Bandung, Kabupaten Bogor, Kabupaten Bandung. Kasus TB di tiga Kabupaten/Kota tersebut berkisar antara 9-12 \% dari jumlah kasus baru di Jawa Barat. Angka Notifikasi Kasus (Case Notification Rate/CNR) TB di Kabupaten Bogor tahun 2016 sebanyak 166 kasus, dimana pada tahun 2017 terdapat peningkatan kasus menjadi 190 kasus (Dinas Kesehatan Jawa Barat, 2017; Dinas Kesehatan Kabupaten Bogor, 2018).

Jumlah penduduk di Kabupaten Bogor pada tahun 2017 adalah 5.715.009 jiwa atau $11,89 \%$ dari jumlah penduduk Jawa Barat. Dimana jumlah penduduk yang cukup besar terdapat di daerah kecamatan cibinong yaitu sekitar 427.014-453.696 jiwa (Dinas Kesehatan Kabupaten Bogor, 2018). Kondisi lingkungan di daerah kecamatan cibinong masih kurang baik, salah satunya masih banyak individu yang membuang sampah sembarang. Lingkungan masyarakat maupun lingkungan rumah yang kumuh, memiliki ruangan tanpa sirkulasi udara serta pencahayaan yang kurang dan padatnya penduduk merupakan salah satu faktor penyebab terjadinya penyakit TB. Salah satu faktor penyebab penyakit TB yaitu lingkungan yang kurang baik. Merokok dan mengkonsumsi alkohol juga dapat menyebabkan penyakit TB. Pekerja kesehatan dapat berisiko tertular Mycobacterium tuberculosis dari individuindividu atau pasien dengan TB telah disadari sejak bertahun-tahun yang lalu. Risiko tersebut semakin meningkat seiring dengan semakin tingginya angka pasien yang terinfeksi oleh TB (Kementerian Kesehatan RI, 2016; Dinas Kesehatan Kabupaten Bogor, 2018).

Laboratorium kesehatan sebagai unit pelayanan penunjang medis, diharapkan dapat memberikan informasi yang teliti dan akurat tentang aspek laboratoris terhadap spesimen/sampel yang pengujiannya dilakukan di laboratorium oleh seorang Ahli Teknologi Laboratorium Medis (ATLM). Salah satu tugas pokok dan fungsi/kewajiban ATLM yaitu harus menguasai ilmu pengetahuan yang berkaitan dengan tugas pokok dan fungsinya di laboratorium serta menerapkan Standar Operasional Prosedur (SOP) yang benar (Kementerian Kesehatan RI, 2007; Pemerintah Republik Indonesia, 2014).

Salah satu spesimen TB yang diperiksa adalah spesimen sputum di laboratorium. Spesimen sputum merupakan bahan infeksius, dimana penanganan sampel sputum ini harus ditangani dengan hati-hati oleh ATLM, untuk mengurangi terjadinya kesalahan atau kecelakaan kerja serta terjadinya infeksi nosokomial dalam penanganan sampel sputum, maka perlu adanya edukasi dari ATLM mengenai penanganan sampel sputum yang baik kepada pasien TB maupun Suspect TB. (Hasugian, 2016). Edukasi mengenai bagaimana cara penanganan sampeldan pengambilan sampel sputum yang baik serta edukasi terkait ciri-ciri sputum yang benar seperti berwarna kuning kehijauan, dahak bercampur darah dan bukan air liur (Ekawati, 2018; Bagian Mikrobiologi, 2017).

ATLM memerlukan suatu pedoman atau petunjuk pemeriksaan laboratorium yang disebut SOP laboratorium. SOP merupakan bagian dari komponen mutu laboratorium TB yang disusun sebagai acuan bagi ATLM dalam melakukan pemeriksaan mikroskopik TB diberbagai tingkat pelayanan sehingga kualitas pemeriksaan laboratorium TB terjamin (Kementerian Kesehatan RI, 2007; Pemerintah Republik Indonesia, 2014). Disamping itu pengetahuan merupakan hasil tahu, dimana dihasilkan setelah orang melakukan pengindraan terhadap suatu objek tertentu. Sehingga tidak adanya pengetahuan seseorang, maka seseorang tersebut tidak mempunyai dasar untuk mengambil keputusan dan menentukan tindakan terhadap masalah yang dihadapi. Sedangkan sikap (attitude) merupakan suatu perbuatan atau tingkah laku sebagai reaksi (respons) terhadap sesuatu rangsangan atau stimulus, yang disertai dengan pendirian dari perasaan seseorang. 
(Notoatmodjo, 2007; Putra 2020). Pengetahuan dan sikap merupakan hal yang terpenting yang harus dimiliki oleh petugas kesehatan dalam menjalankan SOP. Pelayanan kesehatan yang baik bermula dari peningkatan kepatuhan ATLM terhadap standar pelayanan medis, apabila petugas laboratorium mematuhi dan mengikuti semua prosedur atau standar pelayanan kesehatan dengan baik, maka pasien diharapkan dapat memiliki kesempatan untuk sembuh lebih banyak dan angka kesakitan serta kematian pun akan menurun (Musdalifah, 2018).

\section{METODE}

Penelitian ini menggunakan data primer dengan desain penelitian cross sectional. Teknik yang digunakan dalam penelitian ini adalah purposive sampling, dimana teknik penentuan sampel dengan pertimbangan tertentu atau pertimbangan sendiri secara sengaja dalam memilih anggota sampel yang dianggap dapat memberikan informasi yang diperlukan atau unit sampel yang sesuai dengan kriteria inklusi penelitian (Setiaman, 2020). Kriteria inklusi pada penelitian ini yaitu ATLM yang bekerja di Laboratorium Puskesmas atau Rumah Sakit di daerah Kecamatan Cibinong, minimal lulusan DIII Analis Kesehatan. Jumlah ATLM keseluruhan yang bekerja di Laboratorium Puskesmas dan Rumah Sakit di daerah Kecamatan Cibinong yaitu sebanyak 69 orang, dimana 5 orang bekerja di Puskesmas dan 64 orang bekerja di Rumah Sakit. Besar sampel dari penelitian ini dihitung dengan menggunakan rumus Slovin, sehingga di dapatkan hasil besar sampel minimal 40,8 dibulatkan menjadi 41 dari populasi keseluruhan responden. Sampel dalam penelitian ini berjumlah 46 responden ATLM yang bekerja di Puskesmas dan Rumah Sakit daerah Kecamatan Cibinong yang bersedia ikut serta dalam penelitian ini. Penelitian ini dilakukan melalui kuesioner online dengan google form, dimana kuesioner ini di isi oleh ATLM di tempat masing-masing dengan jangka waktu dari bulan Juli sampai Agustus 2020.

Pengumpulan data diawali dengan membagikan kuesioner yang dibuat pada google form dan di sebarkan melalui link google form dengan cara broadcast message kepada rekanrekan ATLM yang sudah bekerja di laboratorium. Sebelum responden mengisi kuesioner terdapat permintaan persetujuan responden apakah bersedia mengisi kuesioner tersebut atau tidak di awal membuka link google form tersebut. Jenis kuesioner yang digunakan oleh peneliti adalah kuesioner tertutup yaitu berupa pernyataan dan pertanyaan yang diberikan kepada responden, kemudian responden harus menjawab pernyataan dan pertanyaan tersebut, setelah itu hasil (jawaban) tersebut dianalisis. Teknik penentuan skor penelitian ini menggunakan skala likert dan guttman. skala likert digunakan untuk mengukur sikap, pendapat dan persepsi seseorang atau sekelompok orang. Dengan skala likert, maka variabel yang diukur dijabarkan menjadi indikator variabel. Pada penelitian ini memakai skala likert menggunakan 4 indikator yaitu : Sangat sesuai, Sesuai, Tidak Sesuai dan Sangat Tidak Sesuai. Untuk setiap item pernyataan atau pertanyaan diberikan skor 1 sampai dengan 4. Sedangkan pernyataan atau pertanyaan yang dibuat dengan skala guttman berisi 2 jawaban alternatif yaitu "setuju" atau "tidak setuju", dimana skala ini digunakan untuk jawaban yang bersifat jelas (tegas) dan konsisten.

Analisis data dilakukan secara univariat dan bivariat (uji regresi). Analisis univariat dilakukan untuk mengetahui karakteristik penelitian, variable independen (Pengetahuan dan sikap) dan variabel dependen (Penerapan penanganan Sampel Sputum Sesuai SOP). Analisis bivariat digunakan untuk menilai hubungan antara variable independen dan variable dependen. Analisis ini bertujuan untuk mengetahui ada tidaknya hubungan pengetahuan dan sikap ATLM terhadap penanganan sampel sputum TB paru. Tingkat kepercayaan pada penlitian ini 95\%, $\alpha=0,05$. Sebelum dilakukan penelitian ini, peneliti sudah mendapatkan izin etik dari RSUD Budi Asih dengan Nomor 173/KEP-ETIK/VIII/2020.

\section{HASIL}

Hasil uji univariat menunjukkan bahwa berdasarkan pengkategorian sub-variable pengetahuan ATLM terhadap SOP penanganan sampel sputum, distribusi frekuensi berdasarkan kategori sebanyak 46 atau $100 \%$ responden memiliki pengetahuan baik terkait penanganan sampel sputum. Distribusi frekuensi berdasarkan kategori sikap. menunjukkan hasil sikap positif sebanyak 4 atau 8,7\% responden sedangkan sikap sangat positif ditunjukkan sebanyak 42 atau 91,3\% responden. 
Tabel 1. Hasil Uji Regresi

\begin{tabular}{lrrr}
\hline $\begin{array}{c}\text { Uji } \\
\text { Regresi }\end{array}$ & Pengetahuan & Sikap & \multicolumn{1}{c}{$\begin{array}{c}\text { Pegetahuan } \\
\text { dan Sikap } \\
\text { terhadap SOP }\end{array}$} \\
\hline Uji Parsial (Uji t) & & & \\
$\mathrm{t}_{\text {hitung }}$ & 2,032 & 2,317 & \\
$\mathrm{t}_{\text {tabel }}$ & 2,017 & 2,017 & \\
Sig t & 0,048 & 0,025 & \\
Uji Simultan (Uji F) & & - & 4,90 \\
$\mathrm{~F}_{\text {hitung }}$ & - & - & 3,41 \\
$\mathrm{~F}_{\text {tabel }}$ & - & - & 0,012 \\
Sig F & - & & \\
Uji & & & \\
$R$ Square & & - & 0,186 \\
$R$ Square & - & - & \\
\hline & & & \\
\hline
\end{tabular}

Hasil uji regresi pada tabel 1 menunjukkan bahwa pada uji $\mathrm{t}$ diketahui nilai sig untuk pengaruh pengetahuan terhadap penerapan SOP sebesar $0,048<0,05$ dan nilai $t_{\text {hitung }} 2,032>\mathrm{t}_{\text {tabel }}$ 2,017. Maka, dapat disimpulkan bahwa terdapat pengaruh antara pengetahuan terhadap penerapan SOP, sedangkan nilai siguntuk pengaruh sikap terhadap penerapan SOP sebesar 0,025<0,05 dan nilai $t_{\text {hitung }} 2,317>t_{\text {tabel }}$ 2,017. Maka, dapat disimpulkan bahwa terdapat pengaruh antara sikap dengan penerapan SOP.

Tabel 1 juga menunjukkan bahwa uji simultan (Uji $\mathrm{F})$ pada penelitian ini melaporkannilai sig pengaruh pengetahuan dan sikap terhadap penerapan SOP sebesar $0,012<0,05$ dan nilai $F_{\text {hitung }} 4,90>F_{\text {tabel }} \quad 3,41$. Maka, dapat disimpulkan bahwa terdapat pengaruh antara pengetahuan dan sikap secara simultan terhadap penerapan SOP, sedangkan pada model regresi ditunjukkan bahwa nilai koefisien determinasi ( $R$-square) sebesar 0,186. Sehingga dapat disimpulkan bahwa besarnya kontribusi pengaruh kedua variabel bebas (pengetahuan dan sikap) terhadap variabel terikat (penerapan SOP) sebesar 0,186 atau 18,6\%.

Hasil dari pertanyaan melalui kuesioner pengetahuan penanganan spesimen sampel sputum TB menunjukkan bahwa semua responden memberi jawaban baik mengenai pengetahuan tentang pentingnya SOP dari mulai pra analitik pemeriksaan sputum, pengumpulan sputum dan ciri-ciri sputum, penyimpanan dan pengiriman sampel sputum.

\section{PEMBAHASAN}

Tenaga Kesehatan termasuk ATLM sering terjadinya kontak erat antara para penderita TB, tindakan seperti pengambilan sampel darah, sputum dan lainnya dapat memicu kecelakaan kerja yang berdampak pada meningkatnya infeksi nosokomial. Pekerja kesehatan berisiko tertularnya Mycobacterium tuberculosis dari individu-individu atau pasien dengan penyakit TB telah disadari sejak bertahun-tahun yang lalu. Risiko tersebut semakin meningkat seiring dengan semakin tingginya angka pasien yang terinfeksi oleh TB. Oleh karena itu, dibutuhkan program pencegahan dan monitoring di setiap fasilitas kesehatan, salah satunya untuk melindungi pekerja kesehatan tersebut. Akan tetapi, program tersebut belumlah tersebar merata disetiap fasilitas kesehatan terutama di negaranegara berkembang (Hasugian, 2016; Kementerian Kesehatan RI 2017; Musdalifah, 2018). Faktor lingkungan seperti, wilayah padat penduduk serta kumuh, ruangan dengan sirkulasi udara kurang baik dan tanpa cahaya matahari. Orang yang bekerja dengan bahan kimia yang berisiko menimbulkan paparan infeksi paru (Kementerian Kesehatan RI, 2017).

Seorang ATLM yang bekerja di sebuah laboratorium dengan penanganan sampel sputum harus memiliki pengetahuan yang baik, sehingga terbentuk suatu perilaku untuk melindungi diri dari lingkungan yang berbahaya saat menangani sampel sputum. Pengetahuan yang kurang akan menyebabkan ATLM menjadi kurang berhatihati dalam bekerja dan meningkatkan resiko terjadinya kecelakaan kerja atau meningkatkan resiko penularan penyakit dari tempat kerja setelah penanganan sampel sputum di kemudian hari. Pengetahuan diperoleh dari pengalaman diri sendiri atau pengalaman orang lain. Tidak adanya pengetahuan seseorang terhadap SOP penanganan sampel sputum TB, maka seseorang tersebut tidak mempunyai dasar untuk mengambil keputusan dan menentukan tindakan yang akan dilakukan terhadap penanganan sampel sputum TB tersebut (Notoatmodjo, 2007; Nurmala, 2018)

Selain pengetahuan, sikap juga sangat mempengaruhi seseorang dalam berperilaku. ATLM yang mempunyai sikap positif akan mendorong ATLM tersebut untuk berperilaku baik dalam bekerja, dalam hal ini ATLM akan menerapkan SOP penanganan sampel sputum TB sesuai dengan SOP yang benar. Sikap yang positif, dimana responden dapat menerima, merespon dan bertanggung jawab terhadap pelaksanaan SOP penanganan sampel sputum yang benar dilaboratorium dari mulai mempersiapkan diri, mempersiapkan alat dan bahan yang akan dipakai dan digunakan di laboratorium sampai dengan pelaporan hasil. Sikap memiliki peranan yang penting karena dapat mempengaruhi perilaku, sikap yang dimiliki oleh seseorang akan menentukan apa 
yang akan mereka lakukan (Mayasari, 2016; Kristiana, 2017).

Penelitian ini dilakukan untuk melihat faktor pengetahuan dan sikap ATLM terhadap SOP penanganan sampel sputum TB paru, namun hasil pada penelitian ini menunjukkan bahwa pengetahuan dan sikap ATLM berpengaruh sebesar $18,6 \%$ terhadap SOP penanganan sampel sputum TB, sedangkan $81,4 \%$ dapat dipengaruhi oleh faktor lain seperti kontak erat dengan pasien $\mathrm{TB}$, faktor usia, faktor jenis kelamin, dimana laki-laki lebih banyak dari pada wanita, karena laki-laki lebih banyak yang merokok, sehingga dapat meningkatkan risiko terkena TB paru 2,2 kali dan minum-minuman alkohol (Kementerian Keseatan RI, 2016; 2017).

\section{DAFTAR PUSTAKA}

Bagian Mikrobiologi. (2017). Buku Panduan Pemeriksaan Sputum BTA. Makassar: Fakultas Kedokteran Universitas Hasanudin.

Dinas Kesehatan Kabupaten Bogor. (2018). Profil Kesehatan Kabupaten Bogor Tahun 2017. Bogor.

Dinas Kesehatan Jawa Barat. (2017). Profil Kesehatan Provinsi Jawa Barat. Bandung.

Ekawati, ER. (2018). Bakteriologi: Mikroorganisme Penyebab Infeksi. Yogyakarta: CV Budi Utama.

Hasugian A R, Vivi L. (2016). Peran Standar Operasional Prosedur Penanganan Spesimen untuk Implementasi Keselamatan Biologik (Biosafety) di Laboratorium Klinik Mandiri. Media Litbangkes, (26)1, 1-8.

Kementerian Kesehatan RI. (2007). Keputusan Menteri Kesehatan RI Nomor 370 Tentang Standar Profesi Ahli Teknologi Laboratorium Kesehatan. Jakarta.

Kementerian Kesehatan RI. (2016). Peraturan Menteri Kesehatan RI Nomor 67 Tentang Penanggulangan Tuberkulosis. Jakarta: Kementerian Kesehatan Republik Indonesia.

Kementerian Kesehatan RI. (2017). Penemuan Pasien Tuberkulosis. Jakarta: Direktorat Jendral Pencegahan dan Pengendalian Penyakit.

Kristiana W. (2017). Pengaruh Faktor Predisposisi Terhadap Kepatuhan Menerapkan SOP APD oleh Petugas Laboratorium di Kabupaten Sukoharjo. [Skripsi]. Surakarta: Program STudi DIV
Keterbatasan pada penelitian ini yaitu peneliti hanya meggunakan responden yang bekerja di Puskesmas dan Rumah Sakit Daerah Kecamatan Cibinong, sehingga tidak dapat mewakili keseluruhan ATLM di Kecamatan Cibinong. Penelitian ini menggunakan kuesioner online sehingga banyak responden yang tidak berminat dalam mengisi kuesioner ini, dikarenakan kesibukannya dalam bekerja.

\section{SIMPULAN}

Terdapat hubungan yang signifikan antara pengetahuan dan sikap ATLM terhadap penerapan SOP penanganan sampel sputum TB.

Analis Kesehatan, Fakultas Ilmu Kesehatan, Universitas Setia Budi.

Mayasari R. (2016). Kejadian Tuberkulosis Paru Pada Pekerja di Laboratorium Mikrobiologi Rumah Sakit Persahabatan Jakarta. [Skripsi]. Jakarta: Fakultas Kedokteran, Program Studi Pendidikan Dokter, Universitas Tanjung Pura.

Musdalifah H S. (2018). Hubungan Tingkat Pengetahuan Dengan Kepatuhan ATLM Dalam Menerapkan Standar Prosedur Operasional Penanganan Spesimen Dahak DI Puskesmas Rujukan Mikroskopis Kabupaten Bulukumba. [Skripsi]. Semarang: Program Studi DIV Analis Kesehatan, Fakultas Keperawatan dan Kesehatan, Universitas Muhammadiyah Semarang.

Notoatmodjo, S. (2007). Promosi Kesehatan dan Ilmu Perilaku. Jakarta: PT. Rineka Cipta.

Nurmala, I. (2018). Promosi Kesehatan. Surabaya: Airlangga University Press.

Pemerintah Republik Indonesia. (2014). UndangUndang Republik Indonesia Nomor 36 Tentang Tenaga Kesehatan. Jakarta

Putra, A.S. (2020). Buku Ajar Promosi Kesehatan. Medan: Fakultas Kesehatan Masyarakat Universitas Islam Negeri.

Setiaman S. (2020). Merancang Kuesioner Untuk Penelitian Bidang Keperawatan. Edisi 1.

World Health Organization. (2019). Global Tuberculosis Report. World Health Organization. 